\title{
Impactos dos leilóes cambiais na trajetória da política cambial brasileira
}

\author{
Geizi Cássia Bettin do Amarante* \\ Julcemar Bruno Zilli**
}

\section{Resumo}

\begin{abstract}
A economia, como ciência, pressupõe a análise sobre causas e efeitos das decisões tomadas pelos agentes econômicos. Tendo em foco a intervenção na taxa de câmbio brasileira, neste trabalho será abordada e contextualizada a estrutura de funcionamento da política cambial no Brasil, bem como o regime cambial e as autoridades responsáveis pelo controle de câmbio. A execução da pesquisa será de maneira exploratória e explicativa, de modo quantitativo. Os resultados encontrados foram obtidos por modelo de vetor autorregressivo (VAR) e demonstraram que todas as variáveis apresentaram raiz unitária, sendo necessário verificar a cointegração das séries, feita por meio do procedimento de Johansen. Os testes apontaram que as séries não são cointegradas e que os leilões à vista apresentaram respostas mais rápidas e significativas no controle cambial.
\end{abstract}

Palavras-chave: Taxa de câmbio. Leilões cambiais. Intervenção.

* Bacharel em Ciências Econômicas pela Universidade de Passo Fundo (UPF) e mestranda no PPGAdm-UPF. E-mail: 126993@upf.br

** Economista. Doutor em Economia Aplicada pela ESALQ/USP. Professor da UPF. E-mail: jbzilli@upf.br

http://dx.doi.org/10.5335/rtee.v25i52.9930

Submissão: 13/09/2019. Aceite: 05/05/2020. 


\section{Introdução}

A ciência econômica revela sua importância por sua história, suas abordagens e, principalmente, pela capacidade de regulação e organização de uma sociedade, sendo essencialmente fundamental para o processo de estruturação de um país. Dentro disso, na divisão macroeconômica, que abrange a economia como um todo, é que se encontram as principais políticas que determinam o crescimento e a distribuição da renda nacional.

Nesse sentido, a taxa de câmbio é uma variável macroeconômica de importância que impacta direta e indiretamente nas famílias e nas empresas no seu cotidiano. Entre meio, muitas vezes, ao dilema teórico de crescimento e desenvolvimento econômico, em que é verificado que o crescimento é alicerce para o desenvolvimento, o fato é que a taxa de câmbio se caracteriza como um elemento fundamental para impulsionar qualquer economia, principalmente aquelas com perfil de economias exportadoras ou importadoras.

As economias estão internacionalmente vinculadas por meio do comércio de bens e serviços e pelos mercados financeiros. Denomina-se isso como globalização. Com isso, a taxa de câmbio, além de aproximar o custo real dos bens entre países, está também vinculada com os mercados de ativos nacional e estrangeiro. Simultaneamente, as influências econômicas do exterior exercem efeitos poderosos sobre a economia nacional.

As políticas econômicas adotadas estão interligadas com o regime cambial. A fim de manter o equilíbrio interno e externo, os governos podem intervir no mercado de câmbio, no intuito de limitar o impacto no produto e nos preços das flutuações cambiais decorrentes do mercado. Porém, a intervenção é um movimento delicado, porque muitas vezes não se sabe determinar se a taxa de câmbio se move por conta dos fundamentos ou por razões puramente especulativas.

O regime de câmbio flutuante, adotado para a economia brasileira em 1999, pressupõe, teoricamente, que o Banco Central do Brasil (Bacen) não deveria intervir com operações de compra ou venda de moeda, sendo que as cotações das moedas internacionais flutuarão de acordo com a oferta e a demanda do mercado. Essa mudança ocorreu mediante uma nova política monetária, que aderiu ao sistema de metas de inflação, adotada para perseguir uma maior estabilização de preços.

Na prática, observa-se que acontece o contrário do regime adotado no passado, pois o Bacen habitualmente efetua intervenções no mercado de câmbio para corrigir 
tendências, diminuir a volatilidade cambial e acalmar os mercados em momentos de crise. A relevância da taxa de câmbio na economia e a influência das políticas cambiais e seus impactos influenciaram na escolha desse tema, que, corriqueiramente, está no centro de debates econômicos e também é ponto central na gestão do governo.

Sabendo-se que o governo, em especial o Bacen, dispõe de instrumentos para agir no controle da taxa de câmbio, como leilões no mercado à vista e swaps cambiais no mercado futuro, o volume de leilões negociados é uma ferramenta analisada no decorrer deste trabalho. Tais leilões são usados para conter grandes oscilações, a fim de evitar inflação, proteger os agentes econômicos e manter a liquidez do mercado.

Buscando contextualizar os leilões como ferramenta de intervenção na taxa de câmbio brasileira, e sabendo-se que ocorre o descumprimento integral do regime cambial flutuante adotado, quais são os impactos do volume de leilões ofertados pelo Banco Central na taxa de câmbio real brasileira?

A decisão de intervir na taxa de câmbio com o intuito de intermediar a política monetária, por exemplo, é uma decisão a ser tomada por cada governo. Nesse sentido, o objetivo geral é analisar o impacto dos leilões cambiais na trajetória da política cambial brasileira. Especificamente, os objetivos são: i) analisar os dois principais instrumentos de intervenção utilizados: mercado à vista e futuro; ii) identificar a ocorrência de efeitos diferenciados entre os leilões à vista e futuro; e iii) captar a relação entre expectativa e oscilação na taxa de câmbio.

\section{Referencial teórico}

Neste capítulo será abordada a estrutura de funcionamento da política cambial no Brasil, bem como o regime cambial, as tendências de curto e longo prazos de paridade de poder de compra e, ainda, o papel das expectativas no desempenho das decisões dos agentes econômicos e das políticas cambiais.

\section{O regime cambial brasileiro}

Como bem se sabe, a década de 1990 foi conturbada para a economia brasileira, a incessante busca pelo controle da inflação aliada às crises internacionais fizeram com que o governo abandonasse o regime de câmbio fixo com âncora cambial e aderisse, em janeiro de 1999, ao chamado tripé macroeconômico baseado 
no sistema de metas de inflação, superávit primário e câmbio flutuante. No novo regime, a tendência de valorização do dólar puxada pela pressão internacional fez com que o Bacen intervisse no câmbio tanto no mercado à vista como no mercado futuro, para minimizar a volatilidade do mercado.

Considerando o período de passagem para o regime cambial flutuante da taxa de câmbio brasileira, verifica-se a trajetória da taxa cambial em valor corrente e real, comparadas anteriormente, a fim de equiparar-se a paridade de compra das taxas real e nominal, descontando a inflação do período através do IGP-DI ${ }^{1}$. Vale a ressalva de que essa comparação é importante, pois na taxa de câmbio real a inflação do período está neutralizada, enquanto que a taxa de câmbio nominal é somente a relação entre as quantidades das moedas (Figura 1).

Figura 1 - Trajetória da taxa de câmbio brasileira real e nominal de 1999 a 2014

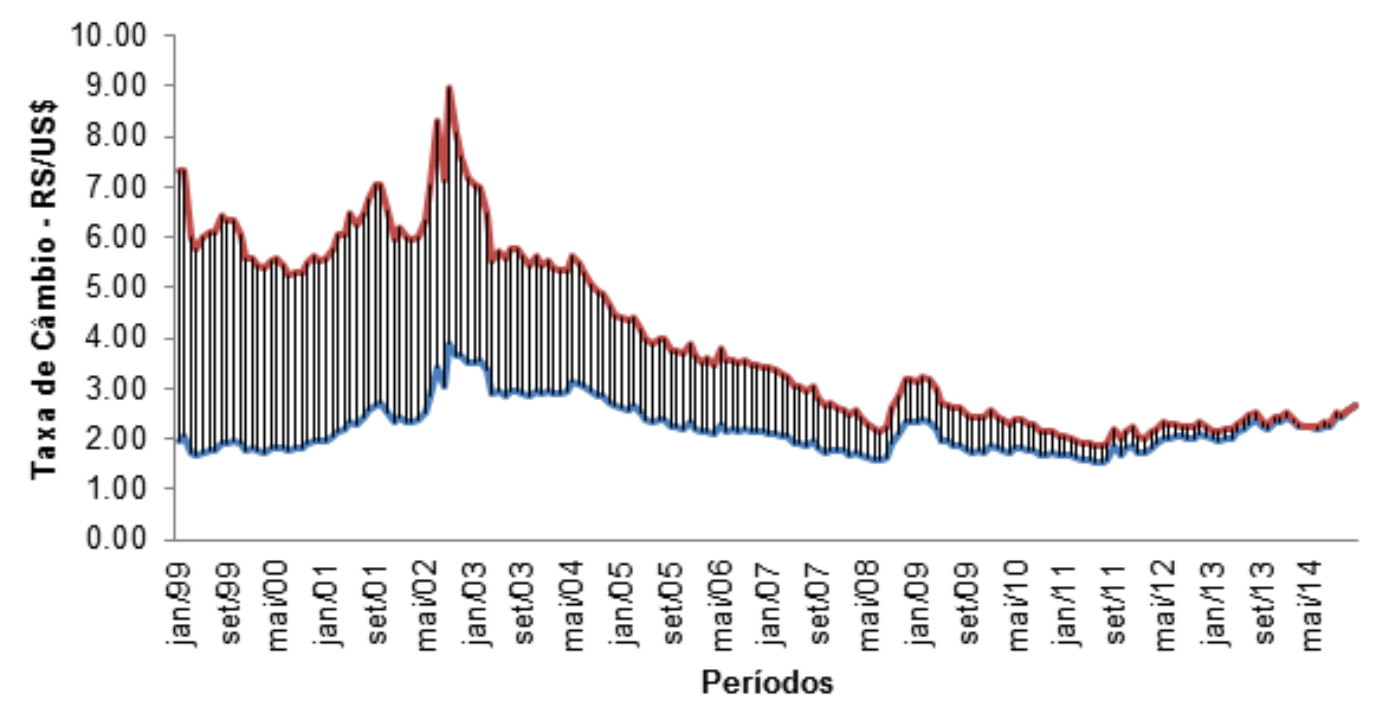

- Nominal —Real

Fonte: elaborada pelos autores com base em Bacen (2015).

O que se pode dizer é que, a partir de então, o sistema de bandas cambiais foi abandonado pelo Banco Central, que simplesmente deixou que o real flutuasse. "O sistema de bandas deu lugar a um regime de flutuação suja. A principal consequência positiva da introdução do regime flexível a partir de 1999 foi a possibilidade de ajuste na conta corrente" (OLIVEIRA; TUROLLA, 2003, p. 203). É justamente 
a partir desse período, quando foi estabelecido o regime flutuante para a taxa de câmbio brasileira, o foco da análise deste trabalho.

Por meio da Figura 1, nota-se o pico de pressão de desvalorização da moeda brasileira, principalmente entre 2001 e 2003, com a crise de desconfiança diante do cenário de incerteza com a troca de governo. Assim como em 2008 e 2009, a desvalorização do real foi motivada pela crise internacional da bolha imobiliária dos Estados Unidos. O objetivo ao deflacionar a taxa de câmbio é revelar a real competitividade da moeda com o dólar, descontando a inflação doméstica. Vale ressaltar que nesse sistema o Bacen não possui uma política cambial explícita, estipula somente a política monetária, controlando a taxa de juros e a base monetária.

Com a adoção de um novo modelo de política econômica, Paula, Pires e Meyer (2008) destacam que houve intensos movimentos de desvalorização em 1999, 2001 e 2002. A mudança de política cambial foi caracterizada por uma alta volatilidade. Paula, Pires e Meyer (2008, p. 3) ainda ressaltam que foi em 2002 que "[...] houve uma notável melhora nas contas externas, devido ao aumento do superávit comercial, favorecido inicialmente pela desvalorização da moeda e posteriormente pelo crescimento da demanda e do nível de preços das commodities no mercado internacional". Portanto, o nível da taxa de câmbio é uma variável fundamental para o crescimento econômico.

Os preços relativos determinam a escolha entre bens produzidos no mercado interno ou no externo. Para Carvalho e Silva (2007, p. 161), "as informações relevantes para a decisão de importar ou exportar são: preços domésticos, preços externos e taxa de câmbio". Além disso, os autores salientam que: "Alterações da taxa de câmbio afetam os preços relativos dos produtos entre o mercado interno e externo, e podem induzir aumento ou redução do saldo comercial" (CARVALHO; SILVA, 2007, p. 161).

Por se tratar de um preço, Maia (2011) acrescenta que, independentemente do regime, as taxas cambiais estão sujeitas à lei da oferta e da procura, do mesmo modo que ocorre com o preço das mercadorias, escassez e excesso de oferta também afetam a taxa cambial, frequentemente por influência de especulações, interferência do governo ou taxa de juros.

A variação das taxas de câmbio, segundo Carvalho e Silva (2007), pode alterar as variáveis econômicas, principalmente em relação ao mercado exterior. As taxas de câmbio são determinadas do seguinte modo: real ou nominal. Como faz notar Mankiw (2010, p. 105), a "taxa de câmbio nominal corresponde ao preço relativo das moedas correntes de dois países". Nada mais é que a taxa com base na qual as pessoas

Teoria e Evidência Econômica - a. 25, n. 52, p. 128-154, jan./jun. 2019 
comercializam a moeda corrente de um país em troca pela moeda corrente de outro país, determinada pela taxa de câmbio real e dos níveis de preços nos dois países.

Seguindo a mesma linha de considerações, Mankiw (2010) também salienta que taxa de câmbio real se refere à troca de bens de um país por bens de outro país específico. E, muitas vezes, a taxa de câmbio real é considerada por termos de troca ou termos de comércio. É igual à taxa de câmbio nominal multiplicada pela proporção entre os níveis de preços nos dois países.

\section{Operações de swap}

No regime cambial brasileiro, alguns instrumentos financeiros de operações no mercado vêm ganhando mais força, possibilitando novas combinações. Algumas novidades propagam-se rapidamente, como no caso dos swaps que estão sendo cada vez mais negociados. Um exemplo disso que ocorre bastante é o swap cambial, em que o Bacen oferece ao investidor uma proteção contra a alta da moeda norte-americana, tornando desnecessária a compra do dólar à vista naquele momento.

Com a introdução de contratos derivativos nos mercados financeiros mundiais, constatou-se crescimento significativo nas negociações de contratos que derivam de ativos subjacentes, taxas de referência ou índices, conforme salientam Maciel et al. (2012). Com enfoque na volatilidade dos preços, Maciel et al. (2012, p. 804) também concluíram que "a introdução e/ou crescimento da negociação dos derivativos não levam ao aumento da volatilidade dos preços no mercado”, mas, em momentos de crise, isso pode não se confirmar.

Geralmente, este movimento de reversão de posições leva a uma intensificação na volatilidade dos preços futuros, o que pode causar uma desestabilização no mercado à vista. Com isso, o swap surge como uma garantia de troca, uma variação cambial por uma taxa de juros pré-fixada. Com a introdução dos swaps de moedas, o comércio internacional passou a ancorar-se em moedas mais fortes, permitindo o fluxo dos negócios.

De uma forma geral, segundo Marques (2013), os primeiros derivativos que surgiram foram os mercados futuros e de opções, criados com o objetivo de proteger a comercialização de produtos agrícolas de variações bruscas no mercado. Em seguida, surgiram os swaps, que são as trocas de fluxos de pagamentos.

Com a reorganização do sistema financeiro mundial por volta dos anos 1970, Marques (2013) ressalta que os bancos e seus clientes começaram a demandar 
formas mais eficientes de financiamento e proteção para os seus investimentos. Os tipos mais comuns de instrumentos financeiros derivativos são os contratos futuros, opções, swaps e contratos a termo.

Vale ressaltar que foi também na década de 1970 que os mercados norte-americanos passaram a ver nas opções uma alternativa de investimento e elas foram introduzidas para negociação nos mercados organizados. De forma geral, Marques (2013) considera que os negócios estruturados surgiram em seguida, criando operações individualizadas aos clientes e possibilitando: obter proteção contra flutuações de taxas e de moedas; gerar benefícios contábeis e fiscais; e arbitrar mercados para reduzir custos. Nesse cenário, o mundo financeiro acompanhou a criação de vários tipos e combinações de derivativos.

Visando a proteção contra riscos cambiais, principalmente, no curto prazo, as operações de swap cambial funcionam como um financiamento compreendendo duas moedas diferentes, uma espécie de troca usada principalmente para administração de riscos financeiros. "O swap consiste na compra ou venda de câmbio pronto contra a simultânea venda ou compra de câmbio futuro" (RATTI, 2006, p. 170). São derivativos negociados em contratos, previamente especificados.

A partir da adoção do Regime de Metas para Inflação e do regime cambial flutuante, as atuações do Bacen no mercado de câmbio à vista e no mercado de cupom cambial suscitaram vários questionamentos acerca de seus efeitos. Muito se é discutido, recentemente, acerca dos impactos dos leilões de swap, por isso a relevância dos estudos elaborados com relação a essas operações.

De acordo com Ratti (2006, p. 170), o custo de um swap é compreendido em três aspectos:

a) a diferença entre as taxas pronta e futura da moeda negociada;

b) juros porventura pagos a outra parte para obtenção dos recursos utilizados na operação;

c) o chamado "custo de oportunidade", representado pelos juros que o possuidor obteria em outro tipo de aplicação em lugar de utilizá-los no swap.

Com isso, os swaps desempenham várias utilidades, como reforçar linhas de crédito no exterior em moeda estrangeira, depósito a prazo em troca de juros, aplicações em investimentos, financiamento de exportações e, ainda, as chamadas linhas de swap.

As linhas de swap são comumente utilizadas entre Bancos Centrais. Ratti (2006) nota que os Bancos Centrais acordam em trocar sua própria moeda pela moeda do outro, um montante máximo por um determinado limite de tempo. Isso permite que um

Teoria e Evidência Econômica - a. 25, n. 52, p. 128-154, jan./jun. 2019 
Banco Central amenize a pressão cambial sobre sua própria moeda. São acordos breves, geralmente de três meses, após esse prazo o swap pode ser liquidado ou renovado.

\section{Leilões à vista}

Aliada às operações de contratos de swap cambial, outra ferramenta popular e comumente utilizada são as operações no mercado à vista de câmbio, que geralmente tem liquidação em até dois dias úteis. As ações no mercado à vista têm o propósito de serem mais imediatas. Quando se trata de intervenção no mercado cambial, é muito comum a comparação entre esses instrumentos de intervenção à vista e futura.

Buscando confrontar a eficácia dessas ferramentas, Bastos e Fontes (2014) e Oliveira e Plaga (2011) também fizeram a comparação de mercado à vista e futuro. De acordo com o relatório publicado pelo Bacen de demonstrativo de variação das reservas internacionais no primeiro tópico, que retrata a intervenção do Bacen, classifica-se a atuação em quatro operações: i) a termo; ii) pronto; iii) linhas com recompra; e iv) empréstimos em moeda estrangeira.

Justamente, a maior consequência da intervenção no mercado à vista é a alteração nas reservas internacionais brasileiras. Conforme Bastos e Fontes (2014), as reservas internacionais também têm um papel muito importante na determinação da taxa de câmbio, pois fornecem aos mercados confiança de que o país terá capacidade de honrar seus compromissos externos e promovem confiabilidade sobre a política monetária e cambial.

Em relação à caracterização das intervenções à vista, as principais são as feitas no pronto, que na maior parte do tempo se igualam às intervenções totais. Contudo, segundo Ventura e Garcia (2012), a prática de atuação no mercado à vista vem perdendo espaço, quando comparada ao crescimento de operações no mercado futuro. Em questão de quantidade, as operações no mercado futuro superam, atualmente, os valores do mercado à vista.

Além do câmbio pronto, que, conforme Garcia e Urban (2004), pressupõe liquidação imediata, ocorre semelhante com o leilão de linha. Nogueira (2014) dinamiza que há desembolso de moeda por parte do Bacen e das contrapartes, mas já com previsão de reversão. Esses leilões podem ser divulgados com um dia de antecedência ou para o mesmo dia. Geralmente, são oferecidas até três datas possíveis para a recompra/revenda dos dólares.

No leilão de dólar a termo, Nogueira (2014) relaciona que esse tipo de leilão é aquele em que o Bacen oferece dólares à vista ao mercado, para liquidação em dois 
dias úteis, como é o padrão para as operações interbancárias de dólar no Brasil, ou a termo, para liquidação no prazo determinado no comunicado. A principal característica desse leilão é que ele não é marcado com antecedência. Após o término do período estipulado, o Bacen analisa as propostas recebidas e, normalmente em até cinco minutos após o fim do leilão, envia outro comunicado ao mercado com seu resultado, informando apenas qual foi a taxa de corte definida para aquele leilão. Espera-se que esse tipo de intervenção afete o nível da taxa de câmbio, uma vez que altera a oferta de dólares no mercado à vista de câmbio.

Por fim, sobre os empréstimos em moeda estrangeira, Bastos e Fontes (2014) enfatizam que são empréstimos feitos pelo Bacen, garantidos por títulos soberanos negociados no mercado internacional ou por operações de exportação, cujos recursos devem ser destinados ao financiamento de exportações; ultimamente, das quatro operações de intervenção, os empréstimos ocorrem com menor frequência.

\section{Paridade do poder de compra}

Buscando equiparar o poder de compra entre países, surge a paridade de poder de compra (PPC), conhecida no mundo todo por purchasing power parity (PPP), que gera estimativas de preços de produtos nos países comparando com o dólar americano. É uma forma de relacionar o poder aquisitivo das moedas. Normalmente, essa doutrina se aplica a fim de efetuar comparações internacionais ao nível de poder de compra e bem-estar social entre diferentes países.

Conforme a hipótese conhecida como a lei do preço único, Mankiw (2010) menciona que ela estabelece que o mesmo bem não possa ser vendido por preços diferentes, em lugares diferentes, ao mesmo tempo. Ao referir-se a esse mesmo assunto, Carvalho e Silva (2007, p. 167) afirmam que, "em um mercado integrado, qualquer mercadoria tem um só preço, ou seja, na ausência de barreiras ao fluxo de informações e de mercadorias, não é possível que um mesmo bem seja vendido a dois ou mais preços diferentes".

O processo que assegura a vigência da lei do preço único, segundo Carvalho e Silva (2007), é denominado arbitragem. Para Mankiw (2010, p. 113, grifo do autor), a "[...] lei do preço único aplicado ao mercado internacional é conhecida como paridade do poder de compra (PPC)". Aliás, Carvalho e Silva (2007, p. 169) enfatizam que "[...] os preços das mercadorias nos diferentes países dificilmente são iguais, quando expressos na mesma moeda. Devido às imperfeições de mercado, a

Teoria e Evidência Econômica - a. 25, n. 52, p. 128-154, jan./jun. 2019 
arbitragem internacional nunca é perfeita". Ainda, Carvalho e Silva (2007) ressaltam que se pode empregar o conceito de paridade de poder de compra para estimar mudanças na taxa de câmbio real, assim como para corrigir a taxa de câmbio nominal e, desse modo, impedir grandes mudanças na competitividade dos produtos.

Com relação à balança comercial, Mankiw (2010) interpretou que a lei do preço único, aplicada ao mercado internacional, sugere que as exportações líquidas são fortemente sensíveis a pequenas variações na taxa de câmbio real. Essa forte sensibilidade é refletida por uma curva de exportação líquida bastante suavizada.

A taxa de câmbio real é que expressa o poder de compra da moeda nacional em transações externas. Por fim, Mankiw (2010) reafirma que quanto mais a taxa de câmbio real vai se afastando do nível previsto pela paridade de poder de compra, maior é o incentivo para que as pessoas venham a se envolver na arbitragem internacional de bens.

Como bem se sabe, os bens e serviços apresentam preços diferentes entre países, com a paridade de poder de compra é possível equiparar os preços. Alguns autores afirmam que no longo prazo a taxa de câmbio se desloca a um nível em os preços entre os países tornam-se relativos. Contudo, nem sempre essa hipótese é aceita, pois os preços em determinados países podem sofrer influências de fatores como disponibilidade, renda per capita e padrões de compra.

\section{O papel das expectativas}

Muitas das medidas tomadas por um governo em relação à economia, muitas vezes, podem ser movidas pelas expectativas. Inclusive, uma expressão muito utilizada pelos próprios economistas ao tentar explicar tendências, previsões e acontecimentos econômicos é: a expectativa do mercado. Há ainda quem diga que o mercado vive de expectativas, sejam positivas ou negativas. A expectativa do mercado representa a forma como o mercado vê a condução das políticas econômicas do governo. Visto que:

A estabilidade econômica e a confiança dos agentes econômicos na capacidade do Governo de comprometer-se com uma regra de política econômica têm reflexos diretos sobre o mercado financeiro brasileiro. Dada a sua estrutura e dinamismo, esse setor da economia consegue captar, de forma relativamente rápida, as expectativas dos agentes econômicos com relação à condução e aos resultados das políticas econômicas governamentais (PEROBELLI; PEROBELLI; ARBEX, 2000, p. 1). 
Não há como falar de expectativa sem falar em taxa de câmbio e vice-versa, uma variável que de certo modo pode ser considerada o objeto de especulações. Esse tema vem ganhando destaque na teoria econômica e existe também uma teoria, chamada de teoria das expectativas racionais. Essa teoria consiste basicamente na pressuposição de que as pessoas tomam decisões com base num conjunto de informações que possuem no presente, incluindo o que ocorreu no passado e o que esperam que possa vir a acontecer no futuro. Essa teoria está correlacionada com a condução da política macroeconômica, prevê que a tomada de decisão é embasada numa expectativa e não em um fato.

Os modelos de Expectativas Racionais afirmam que as pessoas aprendem muito rapidamente os padrões da atividade econômica, e por isso podem frequentemente antecipar experiências e adaptarem-se às mudanças nas circunstâncias econômicas conforme elas acontecem (SANTOS, 2003, p. 4).

Um exemplo macroeconômico é o sistema de metas de inflação, que se baseia na expectativa de atingir o centro da meta de inflação, que no caso do Brasil é 4,5\% ao ano. Esse sistema é adotado para sinalizar o mercado de que a inflação está sendo controlada. Com relação à taxa de câmbio, por ser um regime de câmbio flutuante, há somente uma estimativa do valor da moeda, e ela pode variar para mais ou para menos, a incerteza pode levar à inflação futura.

Elementos de política macroeconômica servem como referência para o mercado, sinalizando a situação em que se encontram, pois: “A condução apropriada dos instrumentos de política econômica, como a política monetária, fiscal e cambial, é identificada como o elemento crucial para se alcançar a estabilidade econômica" (PEROBELLI; PEROBELLI; ARBEX, 2000, p. 1).

Dessa forma, Carvalho e Silva (2007, p. 200) concluíram que "os investidores formulam previsões para os valores das taxas de juros e de câmbio futuras, com base nos quais decidem que aplicações farão. A taxa de retorno esperada é calculada a partir de uma expectativa na variação cambial".

Não raro, as decisões tomadas pelos agentes econômicos diariamente são baseadas na expectativa. Vale ressaltar que no mercado decisões de consumidores e produtores são tomadas apoiadas no crédito. Logo, o crédito nada mais é que uma aposta de remuneração futura, por meio de juros ou de retorno de investimento. Os empresários gastam na expectativa de capturar lucros, enquanto geram e fazem circular a renda da comunidade. 


\section{Modelos de defasagem distribuída}

Na ciência econômica, é muito comum trabalhar com dados associados ao tempo. Por meio da econometria, é possível efetuar análises quantitativas de fenômenos econômicos. Os dados denominados séries de dados temporais, geralmente, são utilizados para análise de trajetória de uma variável no decorrer do tempo, tal como para estimar previsões futuras.

Efeitos de curto e longo prazos, análise de trajetória de variáveis ou previsões de tendências para o futuro, em economia o papel do tempo é tratado por defasagens, de acordo com Gujarati e Porter (2011). A relação entre as variáveis é a partir da pressuposição de que uma será dependente da outra. Comumente, $Y$ representa a variável dependente ou endógena e $X$, a variável explicativa ou exógena.

As defasagens, segundo Gujarati e Porter (2011), ocorrem principalmente por três razões: psicológicas, tecnológicas e motivos institucionais. A partir disso, foram desenvolvidos modelos para que fosse possível estimar essas defasagens. Um deles é o modelo de defasagens distribuídas. $\mathrm{O}$ efeito de defasagens distribuídas no tempo representa, de acordo com Hill, Judge e Griffiths (2010, p. 370), “[...] quanto da modificação ocorrerá no instante em que ela ocorre, quanto ocorrerá um mês após, quanto ocorrerá dois meses após e assim por diante”. Portanto, uma medida econômica pode não causar reações instantâneas, mas os efeitos vão se dispersando ou se distribuindo por períodos futuros de tempo.

Sintetizando a ideia de defasagem, Hill, Judge e Griffiths (2010, p. 369) exemplificam que "[...] as ações ou decisões econômicas tomadas em um ponto $t$ do tempo afetam a economia não só no instante $t$, mas também nos instantes $t+1, t+2$ e seguintes". Algebricamente, o efeito de uma defasagem nas variáveis pode ser dado como uma modificação na variável $x_{t}$ traz efeitos $y_{t}, y_{t+1}, y_{t+2}$, o inverso também é válido, pode-se dizer que $y_{t}$ é influenciado por $x_{t}, x_{t-1}, x_{t-2}$. Um modelo de defasagens distribuídas exemplificado por Gujarati e Porter (2011) com um número de defasagens $k$ finito no tempo é dado por:

$$
Y_{t}=\alpha+\beta_{0} X_{t}+\beta_{1} X_{t-1}+\beta_{2} X_{t-2}+\ldots+\beta_{k} X_{t-k}+u_{t} .
$$

De acordo com os autores, $\beta_{0}$ é o multiplicador de curto prazo, pois representa a variação média de $Y$ em decorrência da variação unitária de $X$ no mesmo período. Caso a variação ocorra em $X$, a variação média em $Y$ é dada por $\beta_{0}+\beta_{1}$ no próximo 
período, consequentemente $\beta_{0}+\beta_{1}+\beta_{2}$, esses resultados parciais são conhecidos como multiplicadores intermediários. Isso até chegar no $k$ períodos, em que há o multiplicador de defasagem distribuída de longo prazo:

$$
\sum_{i=0}^{k} \beta_{i}=\beta_{0}+\beta_{1}+\ldots+\beta_{k}=\beta
$$

Com base nesse modelo de defasagens distribuídas no infinito, a seguir, atribuindo os mesmos valores a $\beta$, será abordado o método de Koyck. O que se pode notar em relação aos modelos de defasagens distribuídas é que os efeitos das defasagens sobre a variável resposta, conforme razões citadas, mudam de acordo com o problema analisado. Em alguns casos, pode aumentar rapidamente, bem como diminuir progressivamente.

\section{Material e métodos}

A seguir, serão explanados os procedimentos metodológicos, apresentando a proposição e o processo de pesquisa utilizado para verificar a intervenção no mercado cambial. Dentro disso, a questão central deste estudo consiste em analisar o efeito dos leilões cambiais sobre a taxa de câmbio.

Sabendo-se que as intervenções podem ter diversas motivações, objetivos, características e regras, bem como podem ser feitas por meio de vários instrumentos e atuar por diferentes canais, um dos temas mais importantes é a eficácia dessa ação, assim como seus efeitos. A execução da pesquisa, para atingir o objetivo proposto, será de maneira exploratória e explicativa, de modo quantitativo e com procedimento técnico por levantamento.

As varáveis, para serem caracterizadas com tal, precisam conter valores, Marconi e Lakatos (2010, p. 121) sustentam que uma variável pode ser "[...] considerada como uma classificação ou medida; uma quantidade que varia; um conceito operacional, que contém ou apresenta valores; aspecto, propriedade ou fator, discernível em um objeto de estudo e passível de mensuração". Para investigar impactos das intervenções na taxa de câmbio, os dados buscados serão trabalhados por meio de modelos econométricos de séries temporais, utilizando o software Eviews 7.

As variáveis abordadas neste trabalho são: 
a) taxa de câmbio real (dez./2014 = 100) - livre - dólar americano (venda), fim de período, mensal, PTAX800, dados do Bacen (2015). A série foi deflacionada pelo índice IGP-DI, que, por sua vez, é disponibilizado pela Fundação Getúlio Vargas (FGV);

b) swap cambial real (dez./2014 = 100) de contratos de dólar, mensal, dados captados junto ao Bacen (2015, p. 1): "Derivativo financeiro que tem por finalidade promover simultaneamente a troca de ativos financeiros entre agentes econômicos". Visando a proteção contra riscos cambiais principalmente no curto prazo, as operações de swap cambial funcionam como um financiamento compreendendo duas moedas diferentes, uma espécie de troca usada principalmente para administração de riscos financeiros. " $\mathrm{O}$ swap consiste na compra ou venda de câmbio pronto contra a simultânea venda ou compra de câmbio futuro" (RATTI, 2006, p. 170);

c) intervenções do Banco Central (mercado à vista) real, (dez./2014 = 100) mensal, Bacen (2015): os dados disponibilizados fazem parte do relatório demonstrativo de variação das reservas internacionais, módulo 1 , que contém os resultados mensais das atividades do Bacen em relação a taxa de câmbio dos contratos a termo, pronto, linhas de recompra e empréstimos em moeda estrangeira. A série foi convertida de valores em dólar para reais através da taxa de câmbio livre para o fim de período (venda), deflacionada pelo IGP-DI;

d) taxa de juros Overnight/Selic mensal (\%), Ipeadata (2015): é a taxa de juros acumulada ao mês;

e) Índice de Confiança do Consumidor (ICC) do estado de São Paulo, mensal: disponível no Ipeadata (2015), este indicador avalia em pontos o grau de confiança que a população tem na situação geral do país e nas condições presentes e futuras de sua família. Essa variável está sendo usada como uma proxy, não estando disponível a série que compreende o índice em todos os estados brasileiros, usa-se do estado de São Paulo, que é a série próxima à variável desejada.

\section{Resultados e discussão}

A análise empírica desenvolvida por meio de um modelo de vetor autorregressivo (VAR $)^{2}$ neste capítulo revela o processo de análise das variáveis por meio do teste de raiz unitária e ainda as funções de resposta ao impulso, que permitem 
avaliar o comportamento individual das variáveis do sistema em resposta a algum choque em outra variável do modelo.

\section{Análise dos resultados}

O modelo VAR é comumente estimado em modelos que visam captar impactos entre variáveis, bem como em modelos de previsão, em conformidade com Gomes e Fantinel (2011) e D'agostini (2010), citados nos trabalhos empíricos já registrados. Pontualmente, o objetivo geral deste trabalho é exatamente assimilar o impacto dos leilões cambiais na trajetória da política cambial brasileira, de modo que se justifica a escolha do modelo VAR. Para a análise, consideram-se todas as séries em logaritmo neperiano, pois geralmente os modelos logaritmos satisfazem mais pelo fato da constância das variáveis.

Para início da análise do modelo autorregressivo, primeiramente foi efetuada a verificação de como o processo estocástico gerador das séries em estudo se comporta ao longo do tempo, ou seja, identificou-se se as variáveis utilizadas são ou não estacionárias. Sendo não estacionárias, por meio do procedimento de teste de raiz unitária ADF, estacionam-se as séries todas já em logaritmo.

Os resultados encontrados nos testes de raiz unitária de ADF mostraram um forte indicativo de que as séries são integradas de ordem um I(1). Com isso, faz-se o teste de cointegração de Johansen com as séries em logaritmo, para verificar se há algum vetor de cointegração. Os resultados apontaram que as séries são não cointegradas, em conformidade com Gujarati e Porter (2011), isso significa que não há desequilíbrio de longo prazo entre elas. Nesse sentido, observa-se que o modelo não exige a inserção de termo de correção de erro.

Após realizar o teste de estacionariedade, para a escolha da ordem de defasagem a ser utilizada na estimação do modelo VAR, levou-se em consideração a indicação de dois diferentes critérios estatísticos de seleção (Akaike e Schwarz). Ressalta-se que a defasagem do VAR é escolhida quando indicada por todos os testes ou por sua maioria. A indicação foi de 2 defasagens, porém, analisando-se coeficientes, foi optado por 3 defasagens.

Seguindo o raciocínio de impacto entre as variáveis, o modelo estimado exposto na Tabela 1 reporta-se ao objetivo de testar o impacto de cada variável na taxa de câmbio brasileira. Pode-se notar que o impacto mais imediato, na primeira defasagem e sendo significativo a $1 \%$, ou seja, estatisticamente diferente de zero, é

Teoria e Evidência Econômica - a. 25, n. 52, p. 128-154, jan./jun. 2019 
o LCAMBIO (-1) - de um período anterior - explica a taxa de câmbio atual. Assim sendo, pode-se dizer que a diferença da taxa de câmbio do mês anterior causa um impacto na diferença do mês atual, de modo que ela diminua em $R \$ 0.261864$.

Tabela 1 - Estimação do modelo VAR

\begin{tabular}{l|c}
\hline \multicolumn{1}{c|}{ Variáveis } & Coeficientes \\
\hline D(LAVISTA(-1)) & $-0.012193^{* *}$ \\
D(LAVISTA(-2)) & $-0.010032^{\mathrm{ns}}$ \\
D(LAVISTA(-3)) & $-0.007021^{\mathrm{ns}}$ \\
D(LCAMBIO(-1)) & $-0.261864^{* * *}$ \\
D(LCAMBIO(-2)) & $-0.112759^{\mathrm{ns}}$ \\
D(LCAMBIO(-3)) & $0.020289^{\mathrm{ns}}$ \\
D(LICC(-1)) & $-0.063997^{\mathrm{ns}}$ \\
D(LICC(-2)) & $0.032502^{\mathrm{ns}}$ \\
D(LICC(-3)) & $-0.307033^{\text {*** }}$ \\
D(LJUROS(-1)) & $-0.042633^{\mathrm{ns}}$ \\
D(LJUROS(-2)) & $0.034663^{\mathrm{ns}}$ \\
D(LJUROS(-3)) & $-0.075885^{\mathrm{ns}}$ \\
D(LSWAP(-1)) & $-0.003931^{\mathrm{ns}}$ \\
D(LSWAP(-2)) & $0.015732^{\mathrm{ns}}$ \\
D(LSWAP(-3) & $0.011447^{\mathrm{ns}}$ \\
\hline
\end{tabular}

Fonte: elaboração dos autores com os dados da pesquisa.

Critérios de informação de Schwarz (SC); * Significativo a 10\%; ** Significativo a 5\%; ** Significativo a $1 \%$; " ns Significativo.

Para tal impacto, na tentativa de interpretar o sinal obtido, supõe-se dois cenários possíveis: se o dólar valorizar em 1\%, o real se desvaloriza (perde valor ante o dólar) em $\mathrm{R} \$$ 0.261864; e se houver um aumento na oferta de dólares no Brasil em $1 \%$, a taxa de câmbio irá apresentar uma queda de $\mathrm{R} \$ 0.261864$, em razão de que seria necessária uma quantidade menor de reais para se adquirir um dólar. Dessa forma, o sinal menos é analisado sob a possibilidade de impactos positivos e negativos.

No primeiro cenário, pressupõe-se que o sinal negativo represente perda de um mês para o outro. Bittencourt, Larson e Thompson (2007) exploraram impactos da volatilidade cambial, citando que a valorização do dólar acarreta perdas na renda nacional, porque encarece as importações e afeta o poder de compra do brasileiro. Aliado a isso, o processo de ajustes dos preços na economia doméstica está relacionado com a taxa de câmbio. Dornbusch, Fischer e Startz (2013) exemplificaram 
que a taxa de câmbio elevada pode impactar negativamente no poder de compra da moeda nacional, principalmente com aumento no índice de inflação.

Não obstante, o sinal negativo pode significar uma relação inversa, a valorização do real pode estar relacionada ao cenário em que se encontra a economia brasileira, conforme sugeriu Leite (2007), dado que um cenário interno otimista de crescimento faça com que mais dólares sejam investidos no país. Para Silva (2011), a queda do dólar ante o real ocorre quando a oferta é maior que a demanda, e esse impacto de queda pode ser notado no curto prazo, ou seja, de um mês para o outro.

Da mesma forma, significativo a $1 \%$ está o LICC de três meses atrás, sabendo-se que eles se relacionam em uma função inversa, o sinal obtido era esperado, dado que o aumento de $1 \%$ no ponto do índice de confiança do consumidor para com o futuro impacte numa desvalorização ou redução do dólar em $R \$ 0,307$. A valorização do real anima os consumidores, pois possibilita desde um aumento de consumo de bens importados até a oportunidade de viajar para o exterior, tendo em vista que os preços estarão mais acessíveis.

Analisando o comportamento da confiança do consumidor e do empresário, Hofmann (2012) observou que as variações nos indicadores de preços parecem exercer mais influência na confiança dos consumidores do que as variáveis de renda e emprego. Sabendo-se que a taxa de câmbio é o preço de troca entre duas moedas, confirma-se o resultado encontrado de que o aumento no LICC impactará na queda de LCAMBIO, em vista de que a expectativa de um cenário econômico positivo seguirá de aumento na entrada de dólares no país, aumentando a oferta.

A relação inversa entre a taxa de câmbio e o índice de confiança dos consumidores também foi denotada por Galhardo (2015), Graner (2015) e Fiesp (2014). Considerando os cenários econômicos de seus trabalhos, os autores supracitados afirmaram que cenários positivos fazem com que as expectativas dos consumidores apresentem tendência de aumento e, simultaneamente, uma menor volatilidade na taxa de câmbio. $O$ inverso é válido, incerteza e pessimismo com o cenário, a confiança diminui e a volatilidade cambial aumenta com tendência de elevação da taxa.

A variável que retrata os valores da intervenção do governo no mercado à vista de câmbio, LAVISTA é significativa ao nível de 5\% (Tabela 1), o que enfatiza a relação de impacto entre as duas variáveis, LCAMBIO e AVISTA. A intervenção no mercado de câmbio à vista do mês anterior faz com que, no presente, a taxa de câmbio seja 1,2\% menor do que no mês anterior, validando a justificativa desta ferramenta muito usada para conter a volatilidade cambial no Brasil.

Teoria e Evidência Econômica - a. 25, n. 52, p. 128-154, jan./jun. 2019 
Diversas são as motivações para as intervenções na taxa de câmbio. Bastos e Fontes (2014) chegaram ao resultado de que a intervenção no mercado à vista reage com maior rapidez à volatilidade cambial. Do mesmo modo, Novaes e Oliveira (2004) e Fiesp (2014) chegaram a resultados semelhantes em seus trabalhos. Independentemente de caracterizar um período de crise cambial ou não, os autores salientam que na maioria das vezes os resultados mais significativos advêm da intervenção no mercado à vista.

\section{Impulso e resposta}

No contexto de um modelo VAR, mesmo que se tenham testes de causalidade, é interessante fazer uma análise nas variáveis em que seja possível capturar um impacto ou efeito causado pela mudança em uma das variáveis, considerando a condição de ceteris paribus, para as demais variáveis. Essa é a denominada análise de resposta ao impulso. Conforme as Figuras 2, 3 e 4, a seguir, será denotada a resposta de todas as variáveis ao impulso do LCAMBIO, sendo então que em cada análise, na Figura 2, apresenta-se a linha azul como a trajetória da variável e as linhas pontilhadas, dois desvios padrão.

Figura 2 - Resposta do câmbio e da intervenção à vista a um choque no câmbio
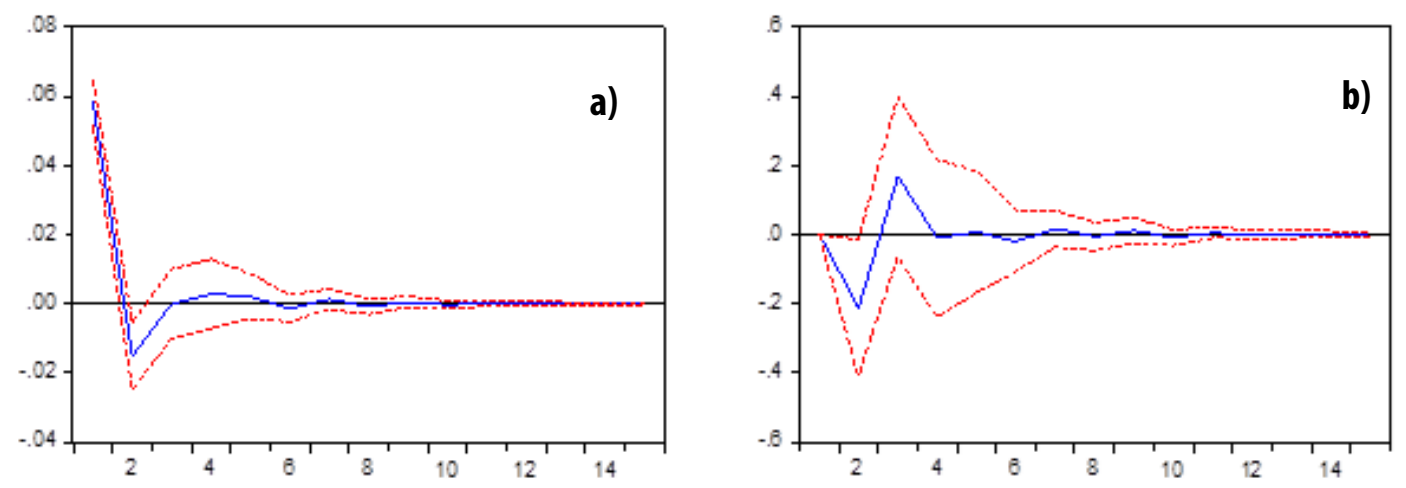

Fonte: elaboração dos autores com dados da pesquisa, 2015.

Como pode ser notado na Figura 2 (a), um choque inesperado no valor de um desvio padrão na variável LCAMBIO sobre o próprio LCAMBIO inicialmente faz com que a taxa de câmbio oscile bruscamente de positiva para negativa. A 
estabilização ao choque de impulso é alcançada, aproximadamente, a partir do quarto período, isto é, após quatro meses, a taxa de câmbio terá absorvido ao choque sofrido inesperadamente. Nesse caso, a taxa de câmbio brasileira sofreria uma pequena valorização ante o dólar, pois, nos períodos iniciais de absorção ao choque, com a queda da taxa de câmbio, seria possível cambiar um dólar com menos valor em reais com relação ao período anterior ao choque.

Esse resultado é semelhante aos resultados encontrados por Marinho e Teixeira (2010) e Maia e Ramalho (2006), entretanto, o que difere este estudo do trabalho dos autores é o tempo de absorção do choque. Neste teste, em aproximadamente quatro meses, o impacto estará neutralizado, enquanto que no trabalho de Marinho e Teixeira (2010), levaria aproximadamente 25 meses. Ressalta-se que nos trabalhos já registrados os autores mencionaram que, após o choque, o novo equilíbrio alcançado é diferente do equilíbrio inicial.

A resposta da intervenção LAVISTA do governo em relação ao LCAMBIO pode ser analisada na Figura 2 (b). Com um impulso ocasional na taxa de câmbio brasileira, o volume de intervenção no mercado à vista de dólar por parte do governo tende a estar negativa nos dois primeiros meses, considerando que um valor negativo represente que o governo tenha que comprar dólares para segurar a volatilidade da taxa de câmbio, consequentemente, no terceiro e quarto meses, com a elevação positiva representada no gráfico, interpreta-se que a autoridade monetária estará fazendo o inverso, vendendo dólares no mercado à vista; e, a partir do quinto mês, os impactos já estarão praticamente absorvidos.

Vale notar que no Brasil a intervenção no câmbio é quase que constante, de acordo com a resposta de LAVISTA ao impulso de LCAMBIO, os impactos são absorvidos em curto prazo. Assim sendo, é dada como contínua. Para corroborar, Bastos e Fontes (2014) chegaram a uma conclusão similar, sendo que as intervenções têm efeito pequeno e pouco duradouro sobre a taxa de câmbio, o que faz com que tenham de ser continuadas. Ventura e Garcia (2012) obtiveram resultados equivalentes de absorção ao choque.

Em relação à resposta do ICC ao impulso de LCAMBIO (Figura 3 (a)), a tendência é de um impacto negativo ao índice de confiança do consumidor, de modo que faz sentido ao conceito do ICC, se houver um impacto de aumento na taxa de câmbio brasileira (desvalorização do real), a tendência é que a confiança do consumidor obtenha uma redução, visto que a desvalorização impacta ao consumidor de diversas formas, mas principalmente pela inflação, ocasionando uma perda de poder de 
compra ao consumidor. A oscilação do índice continua levemente até aproximadamente o nono mês, após esse período o impacto estará praticamente amenizado.

Figura 3 - Resposta do ICC e dos juros ao impulso do câmbio
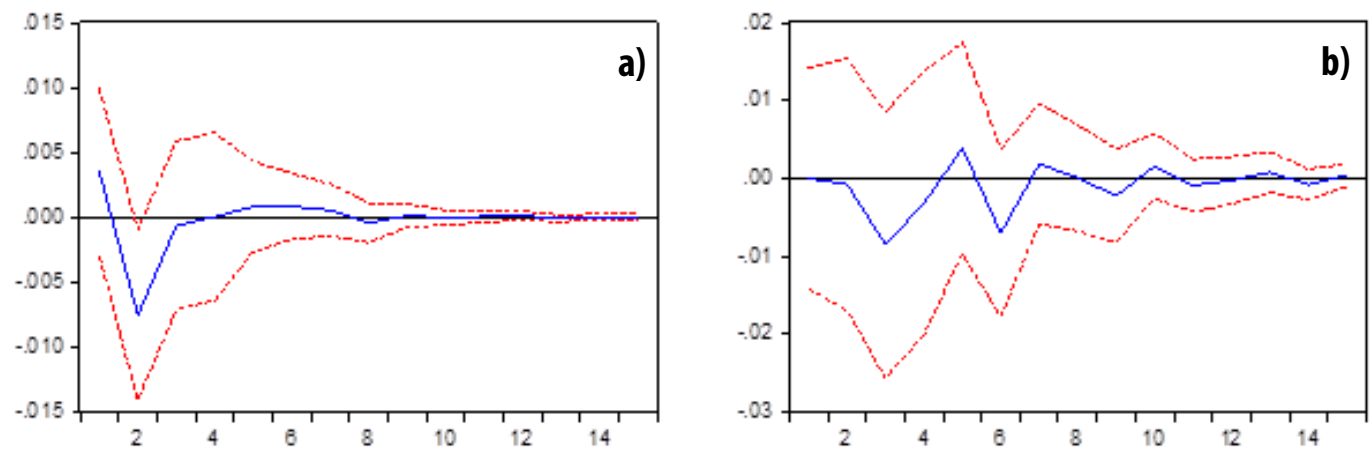

Fonte: elaboração dos autores com dados da pesquisa, 2015.

Choques de incerteza são relevantes para explicar a dinâmica da atividade econômica no Brasil, conforme destacou Costa Filho (2014), os resultados sugerem uma relação entre choques de incerteza e choques de confiança com a taxa de câmbio. Nogueira, Mori e Marçal (2012) também afirmaram que o ICC absorve um impacto na taxa de câmbio, porém em maior período de tempo, cerca de 16 meses, de acordo com o teste efetuado pelos autores.

Ao se analisar a função de resposta dos LJUROS ao impulso de LCAMBIO (Figura 3 (b)), fica explícito que esse é o maior impacto com maior oscilação entre as variáveis da pesquisa. O impulso na taxa de câmbio leva um período de tempo maior para amenizar os impactos na taxa de juros, o choque leva, aproximadamente, dez meses para se dissipar totalmente. Pode-se justificar isso pelo fato de que ligada à taxa de câmbio e juros há uma terceira variável: a inflação. Muitas vezes, o Bacen gerencia o diferencial de juros para valorizar o câmbio (e às vezes para evitar desvalorizações) e controlar a inflação.

As estimações de resposta ao impulso de trabalhos semelhantes encontrados apresentaram robustez. O resultado mais próximo e muito semelhante foi o apresentado por Deus (2015). No modelo testado por Tomazzia e Meurer (2009), as variáveis de maior influência na determinação da taxa de juros é ela mesma e a taxa de câmbio. Quando realizados o impulso e a resposta, a taxa de câmbio absorve o impacto da taxa de juros em aproximadamente oito meses. 
A resposta da taxa de juros sobre a taxa de câmbio encontrada por Mendonça (2007) mostra que o efeito de alta na taxa de juros não é eliminado ao longo de 12 meses. $\mathrm{O}$ resultado encontrado sugere que a autoridade monetária usa de forma efetiva a taxa de juros para neutralizar pressões inflacionárias oriundas de choques sobre a taxa de câmbio. Um bom exemplo desse procedimento é observado no ano de 2001, quando ocorreu acentuada elevação na taxa Selic para conter os efeitos da desvalorização cambial, provenientes da crise argentina e dos ataques terroristas aos EUA, sobre a inflação.

Na Figura 4, a resposta do LSWAP ao impulso de LCAMBIO revela que, ao sofrer um imprevisto na taxa de câmbio, a reação imediata nos swaps é negativa. $\mathrm{O}$ swap representa a venda de dólares no mercado futuro por parte do governo; quando apresenta valores negativos, representa uma posição comprada, neste caso, no primeiro mês, o governo estaria comprando dólares e, simultaneamente, nos próximos dois meses, vendendo dólares com maior intensidade, e a partir do sexto mês é que o evento estaria praticamente amenizado.

Figura 4 - Resposta do swap ao impulso do câmbio

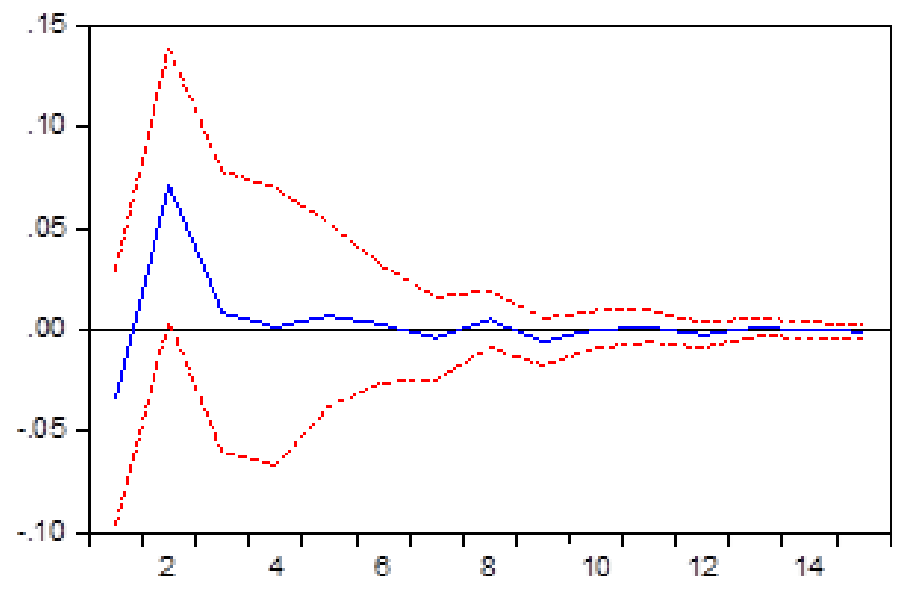

Fonte: elaboração dos autores com dados da pesquisa, 2015.

Concomitante a esse resultado, encontra-se o trabalho de Bastos e Fontes (2014), que encontraram a mesma relação entre swaps e um choque na taxa de câmbio. Assim como Deus (2015), que obteve uma resposta ao impulso da taxa de câmbio bastante semelhante. Tomazzia e Meurer (2009) consideraram relevante o resultado da função de resposta ao impulso entre swap e taxa de câmbio. 
Quando comparadas as respostas das variáveis LAVISTA e LSWAP ao impulso da variável LCAMBIO, nota-se que a LAVISTA reage e absorve os impactos em menor período de tempo, o que não foge à lógica e também ao resultado encontrado na estimativa do modelo VAR, conforme a Tabela 1, em que LAVISTA de um período anterior impacta significativamente no LCAMBIO. Enquanto que LSWAP em momento algum alcançou resultados significativos.

No estudo sobre a eficácia das intervenções do Bacen com ênfase nas crises cambiais, Oliveira e Plaga (2011) observaram que nas crises o instrumento mais eficaz para reduzir a volatilidade da taxa de câmbio foi através de títulos cambiais. Contudo, quando compararam intervenções fora de período de crise, mercado à vista com os swaps cambiais, em maioria o mercado à vista é que se mostrou mais eficaz.

Comparando a correlação entre intervenções e fluxo cambial, Bastos e Fontes (2014) chegaram ao resultado de que os coeficientes de correlação de quando o Bacen intervém no mercado de câmbio pronto e contratado são elevados, enquanto as intervenções por swap mostraram baixa correlação com o fluxo cambial. Com isso, ressalta-se a evidência de que a intervenção no mercado à vista apresenta maior eficácia que a intervenção através do mercado futuro.

As intervenções podem ocorrer tanto por compras e vendas de moeda estrangeira no mercado à vista como por atuações no mercado futuro, ou ainda pela imposição de restrições ao movimento de capitais, vai depender da característica de cada cenário a opção pelo instrumento de intervenção a ser utilizado, de acordo com Fiesp (2014). Inclusive, Novaes e Oliveira (2004) ressaltaram que muitas vezes a intervenção pode ser neutralizada por pressões exógenas.

\section{Considerações finais}

Considerando a teoria da política cambial e dos regimes cambiais e todo o embasamento teórico apresentado, atualmente o regime cambial brasileiro configura-se como flutuação suja. Com isso, é descrita a principal ferramenta utilizada na intervenção pelo Bacen, os leilões cambiais, seja no mercado à vista ou no mercado futuro. Encontram-se alguns estudos semelhantes disponíveis, porém, nenhum corresponde ao objetivo proposto nesta pesquisa.

Uma hipótese sugerida para a intervenção do Bacen na taxa de câmbio é controlar a volatilidade, contudo, independentemente de configurar uma crise cambial 
ou não, o Bacen mantém-se atuando no câmbio constantemente. Dessa forma, o presente trabalho buscou verificar o impacto dos leilões na trajetória da taxa de câmbio brasileira. Para um aprimoramento do estudo, além dos leilões à vista e swap, ainda foram adicionadas na análise as variáveis taxa de juros e índice de confiança do consumidor.

Os resultados obtidos mostraram que, ao longo do período abordado, abril de 2002 a dezembro 2014, os leilões à vista foram significantes na primeira defasagem, causando impactos na taxa de câmbio, já o leilão de swap não apresentou resultados significativos. A taxa de câmbio de um período anterior também apresentou significância de causa de impacto na taxa de câmbio atual, similarmente, o índice de confiança do consumidor na terceira defasagem mostrou-se significativo.

Sendo assim, as variáveis de leilão mercado à vista e swap, as duas formas de intervenção cambial mais utilizadas pelo Bacen, apresentaram impactos significativos, enquanto que swap não causa impactos significativos. Desse modo, afirma-se que a ocorrência de efeitos diferenciados, em que à vista causa impactos na trajetória cambial e swap é insignificante. Foi averiguado também que existe relação entre a expectativa e a oscilação cambial, quando é estatisticamente válido que o índice de confiança do consumidor possa gerar impactos na taxa de câmbio.

É importante ressaltar a análise realizada de resposta ao impulso, em que cada variável do trabalho foi submetida a um choque no valor de um desvio padrão da variável taxa de câmbio. Praticamente todas as variáveis absorveram os impactos de forma similar, taxa de juros é a variável que leva um pouco mais de tempo para absorver totalmente os impactos oriundos do câmbio. Assim, os resultados obtidos sugerem que, quando carecer de uma decisão de intervenção de resultado mais imediato, o Bacen deverá optar por leilões no mercado à vista, com a evidência de essa variável poder amenizar a taxa de câmbio, causando impactos de curto prazo, de um mês para outro. 


\title{
Impacts of exchange auctions on the path of Brazilian exchange policy
}

\begin{abstract}
Economics, as a science, presupposes an analysis of the causes and effects of decisions made by economic agents. With a focus on intervention in the Brazilian exchange rate, this work will address and contextualize the structure of exchange rate policy in Brazil, as well as the exchange rate regime and the authorities responsible for exchange control. The research will be carried out in an exploratory and explanatory manner, in a quantitative way. The results found were obtained by the Autoregressive Vector (VAR) model and demonstrated that all variables had a unit root, being necessary to verify the cointegration of the series, done through the Johansen procedure. The tests showed that the series are not co-integrated and that the spot auctions showed faster and more significant responses in exchange control.
\end{abstract}

Keywords: Exchange rate. Foreign exchange auctions. Intervention.

\section{Impactos de las subastas de intercambio en el camino de la política de intercambio brasileña}

\section{Resumen}

La economía, como ciencia, presupone un análisis de las causas y los efectos de las decisiones tomadas por los agentes económicos. Con un enfoque en la intervención en el tipo de cambio brasileño, este trabajo abordará y contextualizará la estructura de la política cambiaria en Brasil, así como el régimen cambiario y las autoridades responsables del control de cambio. La investigación se llevará a cabo de forma exploratoria y explicativa, de forma cuantitativa. Los resultados encontrados se obtuvieron mediante el modelo de Vector autorregresivo (VAR) y demostraron que todas las variables tenían una raíz unitaria, siendo necesario verificar la cointegración de la serie, realizada mediante el procedimiento de Johansen. Las pruebas mostraron que las series no están cointegradas y que las subastas al contado mostraron respuestas más rápidas y significativas en el control de cambio.

Palabras clave: Tipo de cambio. Subastas de divisas. Intervención.

Classificação JEL: C01, E42. 


\section{Notas}

1 O Índice Geral de Preços - Disponibilidade Interna (IGP-DI) é um indicador do movimento de preços que há mais de seis décadas serve às comunidades econômicas, nacional e internacional, como termômetro de inflação no Brasil. Também é usado como referência para correções de preços e valores contratuais (FGV, 2015).

2 A escolha do modelo VAR deve-se ao fato de que no teste de cointegração as variáveis não apresentam vetor de cointegração; caso existisse vetor de cointegração, deveria ser rodado o modelo vetor autorregressivo com mecanismo de correção de erros (VEC).

\section{Referências}

BACEN. Banco Central do Brasil. 2015. Disponível em: http://www.bcb.gov.br. Acesso em: 19 out. 2015.

BASTOS, E. K. X.; FONTES, P. V. da S. Mercado de câmbio brasileiro, intervenções do banco central e controles de capitais de 1999 a 2012. Ipea, Brasília, v. 1934, n. 85, p. 1-81, fev. 2014.

BITTENCOURT, M. V. L.; LARSON, D. W.; THOMPSON, S. R. Impactos da volatilidade da taxa de câmbio no comércio setorial do Mercosul. Estudos Econômicos, São Paulo, v. 37, n. 4, p. 791816, out. 2007.

CARVALHO, M. A. de; SILVA, C. R. L. da. Economia internacional. 4. ed. São Paulo: Saraiva, 2007.

COSTA FILHO, A. E. da. Incerteza e atividade econômica no Brasil. Economia Aplicada, Ribeirão Preto, v. 18, n. 3, p. 421-453, jul. 2014.

D'AGOSTINI, L. L. M. Modelos monetários para previsão de juros e câmbio pelos métodos VAR e BVAR. 2010. 317 f. Tese (Doutorado em Desenvolvimento Econômico) - Universidade Federal do Paraná, Curitiba, 2010.

DEUS, L. N. Fluxos de capitais e taxa de câmbio no Brasil: uma aplicação do modelo de vetores auto-regressivos (VAR). Economia e Desenvolvimento, Santa Maria, v. 2, n. 26, p. 85-126, jan. 2015.

DORNBUSCH, R.; FISCHER, S.; STARTZ, R. Macroeconomia. 11. ed. Porto Alegre: Amgh Editora, 2013.

FGV. Instituto Brasileiro de Economia. 2015. Disponível em: http://portalibre.fgv.br/main.jsp?lumChannelId=402880811D8E34B9011D92B6B6420E96. Acesso em: 28 set. 2015.

FIESP. Estudos sobre a Taxa de Câmbio no Brasil. 2014. Disponível em: www.fiesp.com.br/arquivo-download/?id=139242. Acesso em: 08 nov. 2015.

GALHARDO, A. Dúvidas sobre os juros nos Estados Unidos. 2015. Disponível em: http://analiseeconomica.com.br/site/duvida-sobre-os-juros-nos-estados-unidos/. Acesso em: 08 nov. 2015.

GARCIA, M. G. P.; URBAN, F. O Mercado Interbancário de Câmbio no Brasil. 2004. 48 f. Curso de Economia, PUC/Rio, Rio de Janeiro, 2004. Disponível em: http:/www.economia.puc-rio.br/ mgarcia/Papers/Garcia\&Urban040325;.PDF. Acesso em: 20 nov. 2015. 
GOMES, É. C.; FANTINEL, V. D. O impacto da taxa de câmbio e da renda mundial nas exportações de calçados gaúchos. 20 f. Curso de Economia Aplicada, PUCRS, Porto Alegre, 2011. Disponível em: http://www.pucrs.br/eventos/eeg/download/Mesa14/O_Impacto_da_Taxa_de_Cambio_e_da_Renda_Mundial_nas_Exportacoes_de_Calcados_Gauchos.pdf. Acesso em: 22 out. 2015.

GRANER, F. Expectativa é de trégua da inflação no bolso dos consumidores em 2016. 2015. Disponível em: http://fatoonline.com.br/conteudo/10887/expectativa-e-de-tregua-da-inflacao-no-bolso-dos-consumidores-em-2016?or=rss. Acesso em: 08 nov. 2015.

GUJARATI, D. N.; PORTER, D. C. Econometria básica. 5. ed. São Paulo: AMGH, 2011.

HILL, R. C.; JUDGE, G. G.; GRIFFITHS, W. E. Econometria. Tradução: Alfredo Alves de Farias. 3. ed. São Paulo: Saraiva, 2010.

HOFMANN, R. M. Comportamento da confiança do consumidor e do empresário industrial brasileiro no período 2010/11. Revista FEE, Porto Alegre, v. 40, n. 1, p. 117-134, jan. 2012.

IPEADATA. Instituto brasileiro de pesquisa econômica aplicada. 2015. Disponível em: http:// www.ipeadata.gov.br. Acesso em: 19 out. 2015.

LEITE, A. A valorização do real: um aspecto positivo da economia brasileira. Revista da Madeira, n. 103, 2007. Disponível em: http://www.remade.com.br/br/revistadamadeira_materia. php?num=1063\&subject=E mais\&title=A valorização do real: um aspecto positivo da economia brasileira. Acesso em: 07 nov. 2015.

MACIEL, L. et al. Impacto dos contratos futuros do Ibovespa na volatilidade dos índices de ações no Brasil: uma análise na crise do subprime. Estudos Econômicos, São Paulo, v. 42, n. 4, p. 801825 , out. 2012.

MAIA, J. de M. Economia internacional e comércio exterior. 14. ed. São Paulo: Atlas, 2011.

MAIA, S. F.; RAMALHO, H. M. de B. Efeitos reais e nominais sobre as flutuações da taxa real de câmbio Brasil/Estados Unidos: um estudo empírico usando VAR (1999-2003). Revista Economia, v. 7, n. 1, p. 59-100, jan./jul. 2006.

MANKIW, N. G. Macroeconomia. 7. ed. Rio de Janeiro: LTC, 2010.

MARCONI, M. de A.; LAKATOS, E. M. Fundamentos de metodologia científica. 7. ed. São Paulo: Atlas, 2010.

MARINHO, E.; TEIXEIRA, M. Os efeitos dos choques reais e nominais sobre as taxas de câmbio no Brasil. Estudos Econômicos, São Paulo, v. 40, n. 3, p. 535-559, set. 2010.

MARQUES, T. de O. O uso de instrumentos financeiros derivativos nos intermediários financeiros listados na BM\&FBOVESPA. 2013. 98 f. Dissertação (Mestrado em Contabilidade) - Programa de Pós-graduação em Contabilidade, Universidade Federal de Santa Catarina, Florianópolis, 2013.

MENDONÇA, H. F. de. Metas para inflação e taxa de juros no Brasil: uma análise do efeito dos preços livres e administrados. Revista Economia Política, São Paulo, v. 27, n. 3, jul. 2007.

NOGUEIRA, L. R. As intervenções do banco central do Brasil no mercado de câmbio e seus efeitos no nível intradiário da taxa de câmbio. 2014. 49 f. Dissertação (Mestrado em Economia) - Curso de Economia, Fundação Getúlio Vargas, Rio de Janeiro, 2014. Disponível em: http://bibliotecadigital.fgv.br/dspace/bitstream/handle/10438/12051/Dissertacao - Leandro Nogueira - Final v4 revisada.pdf?sequence=1\&isAllowed=y. Acesso em: 20 nov. 2015. 
NOGUEIRA, V. de A.; MORI, R.; MARÇAL, E. F. Transmissão da variação cambial para as taxas de inflação no brasil: estimação do pass-through através de modelos de vetores autorregressivos estruturais com correção de erros. Anpec, São Paulo, jan. 2012. Disponível em: http://www.anpec. org.br/encontro/2012/inscricao/files_I/i3-d066806a4388c75673a5f086a7188e40.pdf. Acesso em: 08 nov. 2015.

NOVAES, W.; OLIVEIRA, F. N. de. Intervenções no mercado cambial: eficácia de derivativos de câmbio e de outros instrumentos. Repositório Ipea, Rio de Janeiro, p. 1-32, 19 jul. 2004.

OLIVEIRA, F. N. de; PLAGA, A. Eficácia das intervenções do Banco Central do Brasil sobre a volatilidade condicional da taxa de câmbio nominal. Revista Brasileira de Economia, Rio de Janeiro, v. 65, n. 1, p. 71-92, jan. 2011.

OLIVEIRA, G.; TUROLLA, F. Política econômica do segundo governo FHC: mudança em condições adversas. Tempo Social, São Paulo, v. 15, n. 2, p. 195-216, nov. 2003.

PAULA, L. F. de; PIRES, M. C. de C.; MEYER, T. R. Taxa de câmbio e balança comercial no Brasil: uma análise recente. Anpec, Rio de Janeiro, 2008.

PEROBELLI, F. F. C.; PEROBELLI, F. S.; ARBEX, M. A. Expectativas racionais e eficiência informacional: análise do mercado acionário brasileiro no período 1997-1999. Revista de Administração Contemporânea, Curitiba, v. 4, n. 2, p. 7-27, ago. 2000.

RATTI, B. Comércio internacional e câmbio. 11. ed. São Paulo: Lex Editora, 2006.

SANTOS, N. C. dos. A hipótese de expectativas racionais: teoria e testes. 2003. 99 f. Monografia (Especialização) - Faculdade de Ciências Econômicas, Universidade Federal do Rio Grande do Sul, Porto Alegre, 2003.

SILVA, A. V. da. A influência do dólar na economia brasileira. Meio Filtrante, São Paulo, v. 53, n. 5, nov. 2011.

TOMAZZIA, E. C.; MEURER, R. O mecanismo de transmissão da política monetária no Brasil: uma análise em VAR por setor industrial. Economia Aplicada, Ribeirão Preto, v. 13, out. 2009.

VENTURA, A.; GARCIA, M. Mercados futuro e à vista de câmbio no Brasil: o rabo abana o cachorro. Revista Brasileira de Economia, Rio de Janeiro, v. 66, n. 1, jan. 2012. 